\title{
Erratum: Association of Hemorrhoid Vascular Injuries with Cigarette Smoking-An Evaluation with Interesting Prospects
}

\author{
Savitha V. Nagaraj, MD ${ }^{1}$ Amit Mori, MD ${ }^{2}$ Madhavi Reddy, $\mathrm{MD}^{3}$ \\ ${ }^{1}$ Department of Internal Medicine, The Brooklyn Hospital Center, \\ Brooklyn, New York \\ 2 Department of Gastroenterology, Center for Digestive Disease, \\ Shenandoah, Texas \\ ${ }^{3}$ Department of Gastroenterology, The Brooklyn Hospital Center, \\ Brooklyn, New York

\begin{abstract}
Address for correspondence Savitha V. Nagaraj, MD, Department of Internal Medicine, The Brooklyn Hospital Center, Brooklyn, NY 11201 (e-mail: Savitha.vnagaraj@gmail.com; snagaraj@tbh.org).
\end{abstract} \\ Surg J 2020;6:e10.
}

\section{ERRATUM}

It has been brought to our attention that - Figure $\mathbf{1}$ was incorrect in the above article published online in Volume 5, Issue 4 of The Surgery Journal (10.1055/s-0039-1700497). The correct figure has now been updated as given below.

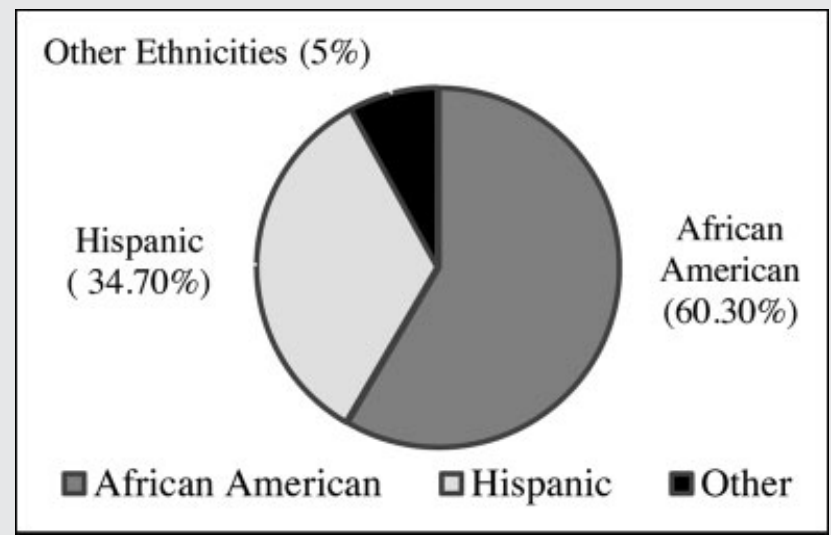

Fig. 1 Pie-graph showing distribution of ethnicities. - Fig. 1 depicts the distribution of ethnicities. Majority of our study population were African American 60.3\% (146/242), followed by Hispanics 34.7\% (84/242) and other ethnic groups 5\% (12/242). 